\title{
Streamlined Human Cell-Based Recombinase-Mediated Cassette Exchange Platform Enables Multigene Expression for the Production of Therapeutic Proteins
}

Seunghyeon Shin ${ }^{1}$, Su Hyun Kim ${ }^{1}$, Jae Seong Lee ${ }^{2^{*}}$, Gyun Min Lee ${ }^{1^{*}}$

${ }^{1}$ Department of Biological Sciences, KAIST, Daejeon 34141, Republic of Korea

${ }^{2}$ Department of Molecular Science and Technology, Ajou University, Suwon 16499, Republic of Korea

\section{Correspondence}

Jae Seong Lee, Department of Molecular Science and Technology, Ajou University, Suwon 16499, Republic of Korea

Email: jaeseonglee@ajou.ac.kr

Gyun Min Lee, Department of Biological Sciences, KAIST, Daejeon 34141, Republic of Korea Email: gyunminlee@kaist.ac.kr 
(a)

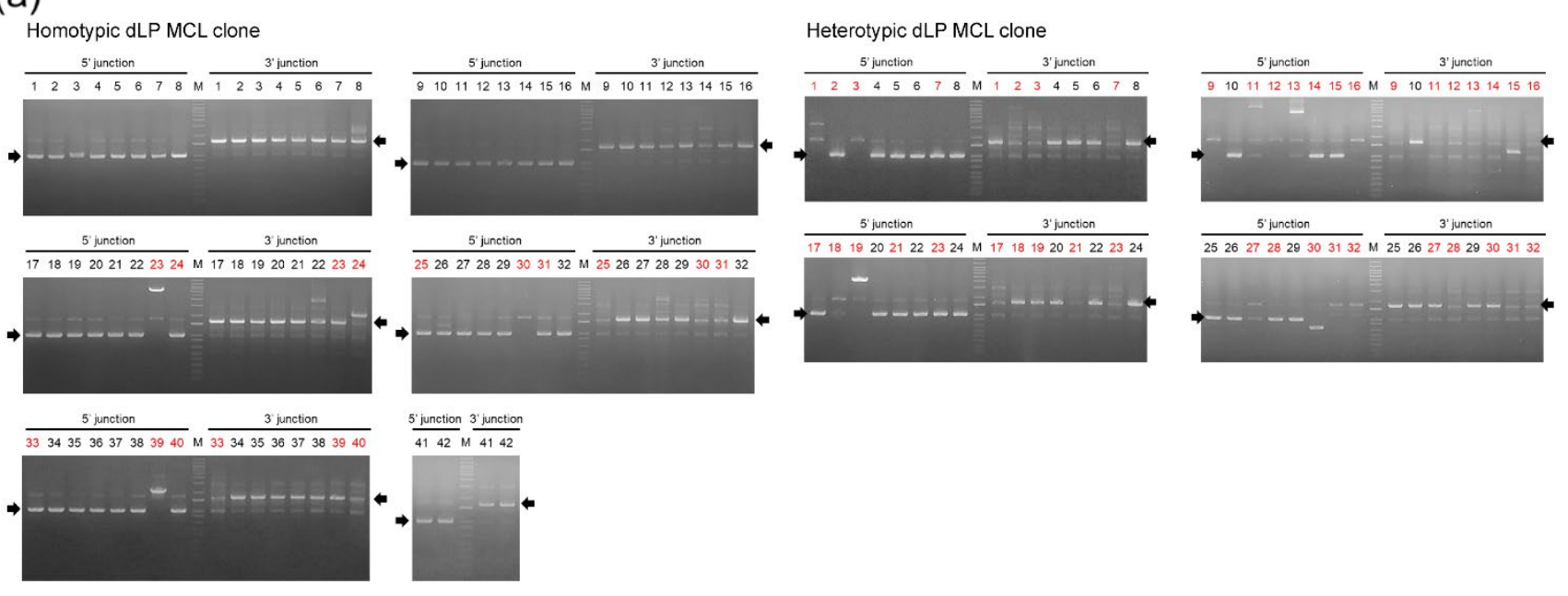

(b)
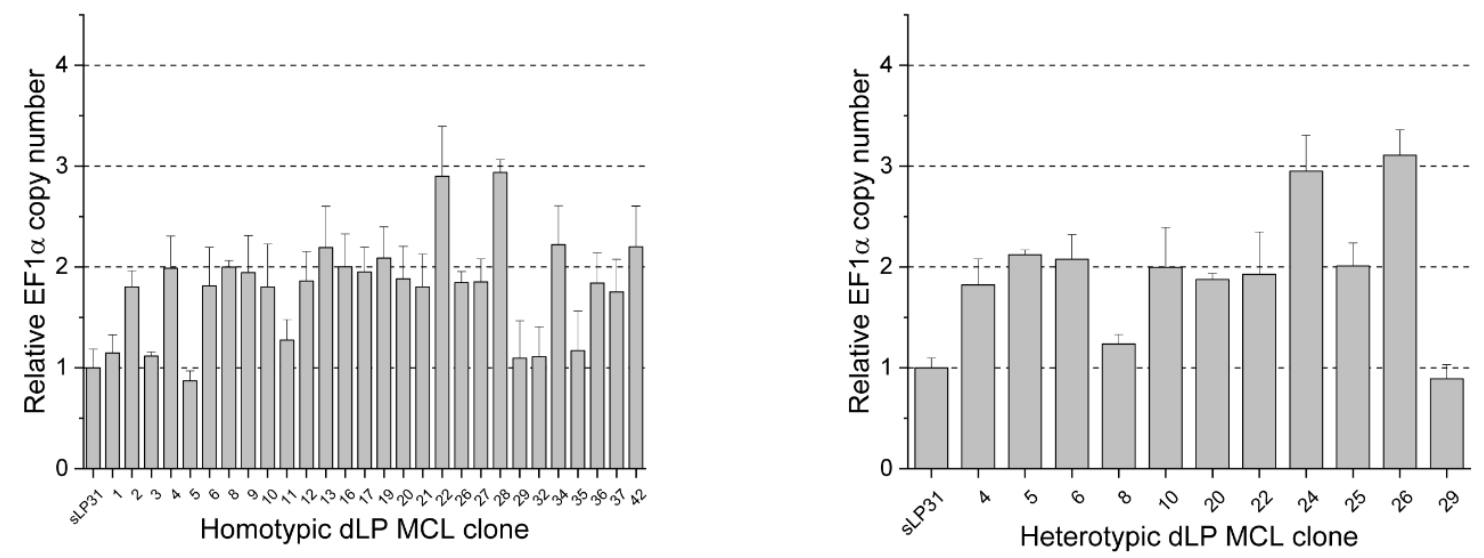

Supporting Figure S1. Generation of dual-landing pad (dLP) master cell lines (MCLs) using the CRISPR/Cas9-mediated integration. (a) Verification of targeted integration at the ROSA26 locus in a single-landing pad (sLP) 31 clone, which harbors a loxP-EF1 $\alpha$-mCherry-lox 2272 landing pad at the AAVS1 locus, by 5'/3' junction PCR. Homotypic and heterotypic dLP MCLs harbors a second landing pad, loxP-EF1 $\alpha$-TagBFP-lox2272 and attP-EF1 $\alpha$-TagBFP-attP ${ }^{\text {mut }}$, respectively, at the ROSA26 locus. Negative clones are shown in red, and black arrows indicate the expected size of the PCR amplicons. (b) Measurement of relative EF1 $\alpha$ copy numbers in stable clones. A genomic DNA sample of the sLP31 clone was used as a reference for the measurement of EF1 $\alpha$ copy number. ${ }^{1}$ Error bars represent standard deviations of three independent experiments. 
(a)

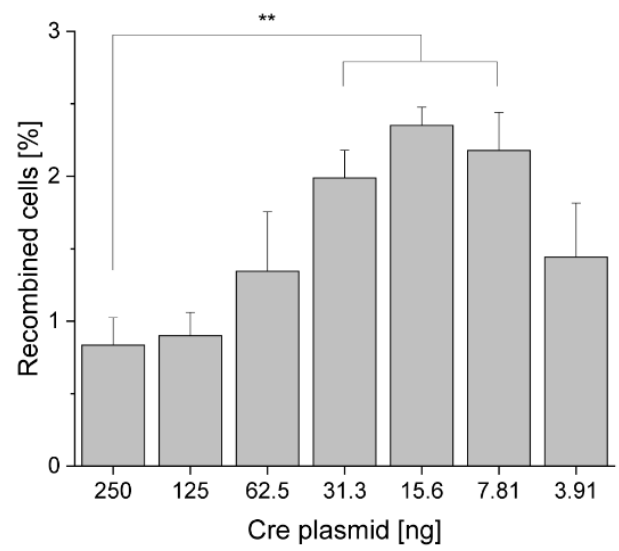

(b)

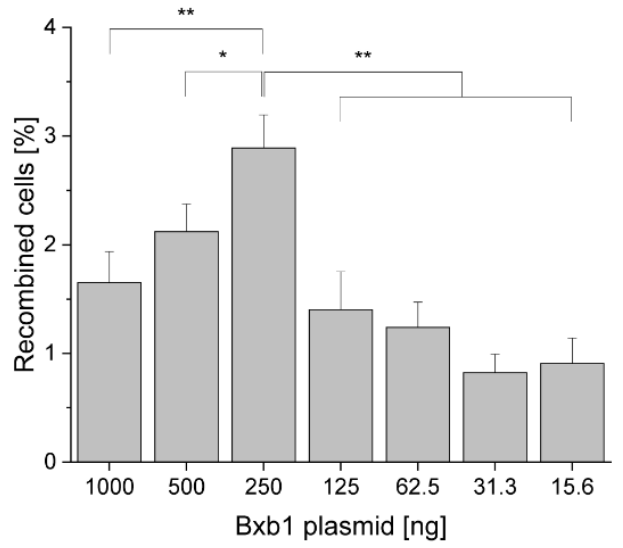

Supporting Figure S2. Titration of recombinase plasmid concentration. The efficiency of RMCE mediated by (a) Cre recombinase or (b) Bxb1 integrase was measured in seven different concentrations of the recombinase plasmid with a fixed amount of donor plasmid $(1 \mu \mathrm{g})$, in sLP or heterotypic dLP MCLs, respectively. RMCE efficiency was determined by calculating the percentage of mCherrynegative and eGFP-positive cells or TagBFP-negative and eGFP-positive cells in the total number of cells. Error bars represent standard deviations of three independent experiments. The data were analyzed using a one-way analysis of variance with Tukey's post hoc test, ${ }^{*} \mathrm{p}<0.05,{ }^{* *} \mathrm{p}<0.01$. 
(a)

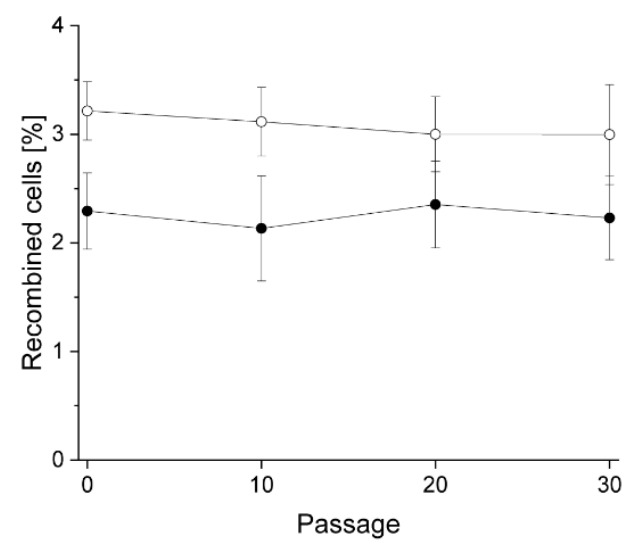

(b)

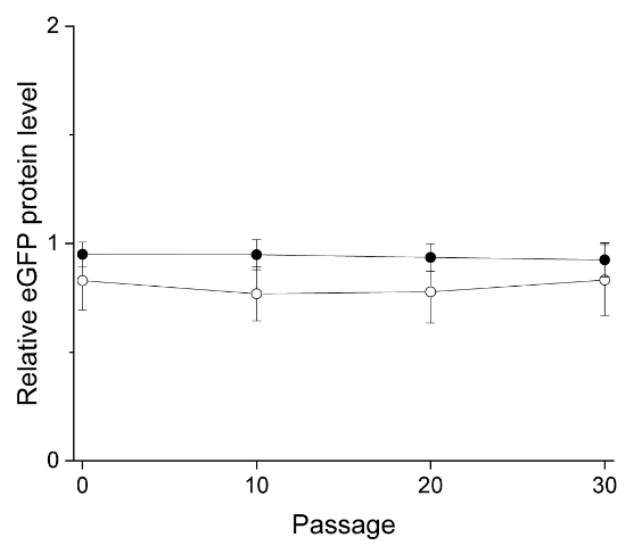

Supporting Figure S3. Stability of recombinant cell pools. (a) Change in the percentage of recombined cells in the total number of cells during long-term culture. mCherry- or TagBFP-negative cells were measured by flow cytometry at passage $0,10,20$, and 30 . (b) Change in the relative eGFP protein levels during long-term culture. eGFP protein levels were measured by flow cytometry at passage $0,10,20$, and 30 , and were normalized to the AAVS1 sample at passage 0 . Cre recombinasemediated RMCE at the AAVS1 locus (black circle) and Bxb1 integrase-mediated RMCE at the ROSA26 locus (white circle). Error bars represent standard deviations of three independent experiments. 

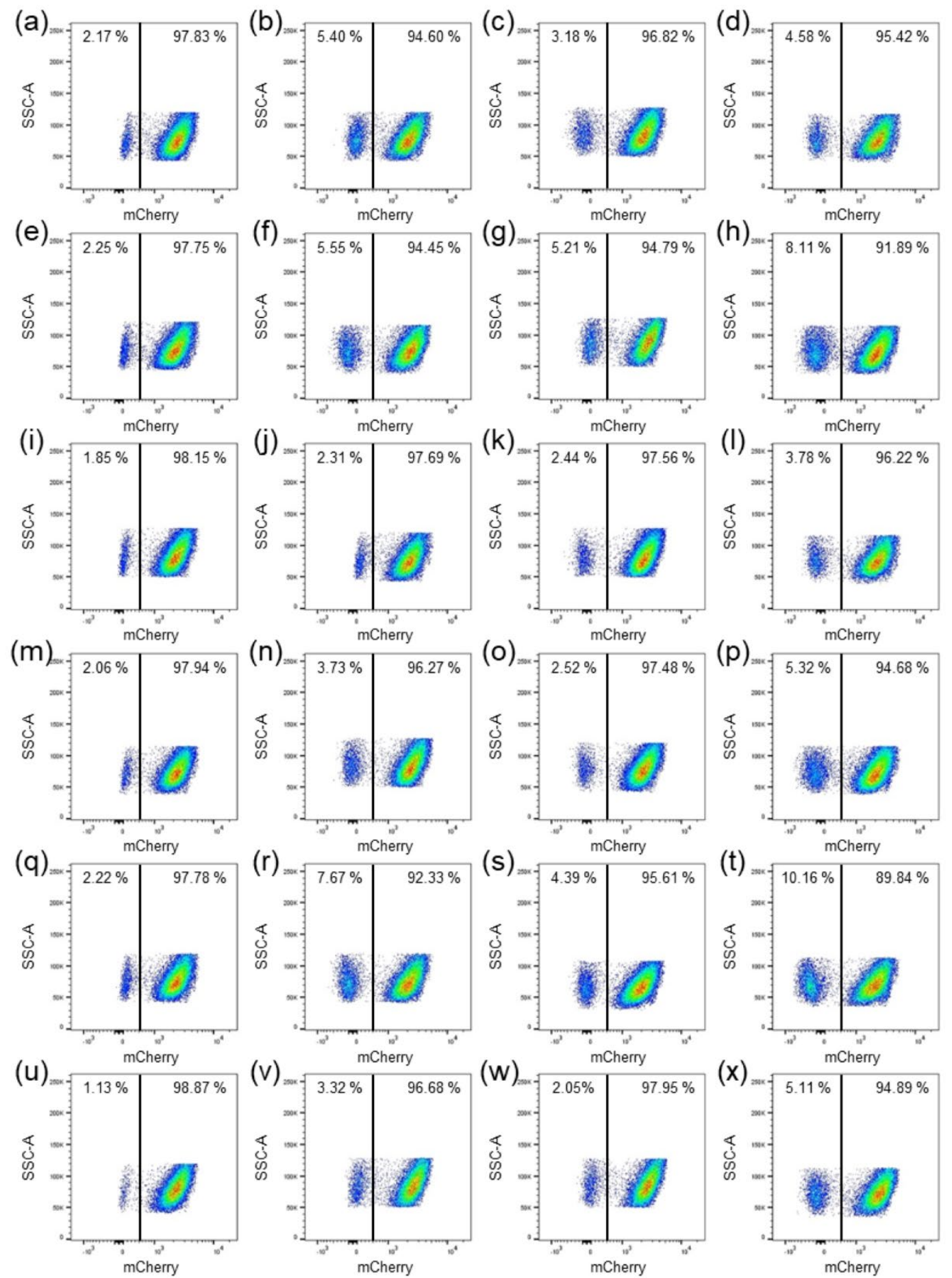

Supporting Figure S4. Representative FACS plots and gates of RMCE in the sLP MCL. eGFP loxPdonor with (a) control, (b) SV40-N, (c) SV40-C, (d) SV40-NC, (e) control, (f) SV40-N, (g) cMyc-N, or (h) NP-N NLS Cre. Control Cre with (i) control, (j) SV40-5', (k) SV40-3', (l) SV40-5'/3', (m) control, 
(n) SV40-5'/3', (o) GRE-5'/3', or (p) NF- B $^{\prime} 5^{\prime} / 3^{\prime}$ DTS loxP-donor. eGFP donor in (q) control, (r) NLS, (s) DTS, or (t) NLS and DTS used. mAb donor in (u) control, (v) NLS, (w) DTS, or (x) NLS and DTS used. 

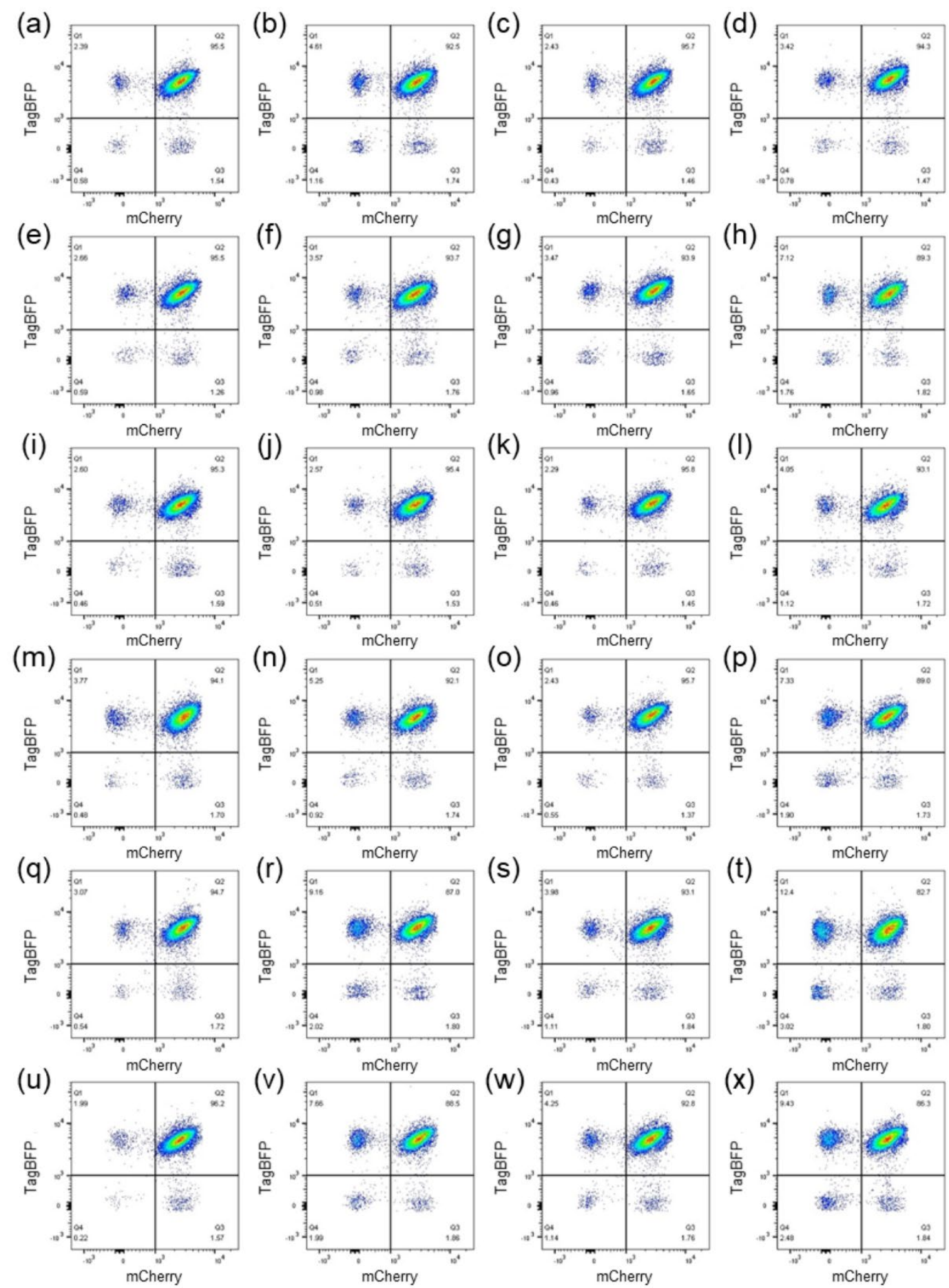

Supporting Figure S5. Representative FACS plots and gates of RMCE in the homotypic dLP MCL. eGFP loxP-donor with (a) control, (b) SV40-N, (c) SV40-C, (d) SV40-N/C, (e) control, (f) SV40-N, (g) cMyc-N, or (h) NP-N NLS Cre. Control Cre with (i) control, (j) SV40-5', (k) SV40-3', (l) SV40- 
5'/3', (m) control, (n) SV40-5'/3', (o) GRE-5'/3', or (p) NF-кB-5'/3' DTS loxP-donor. eGFP donor in (q) control, (r) NLS, (s) DTS, or (t) NLS and DTS used. mAb donor in (u) control, (v) NLS, (w) DTS, or (x) NLS and DTS used. 

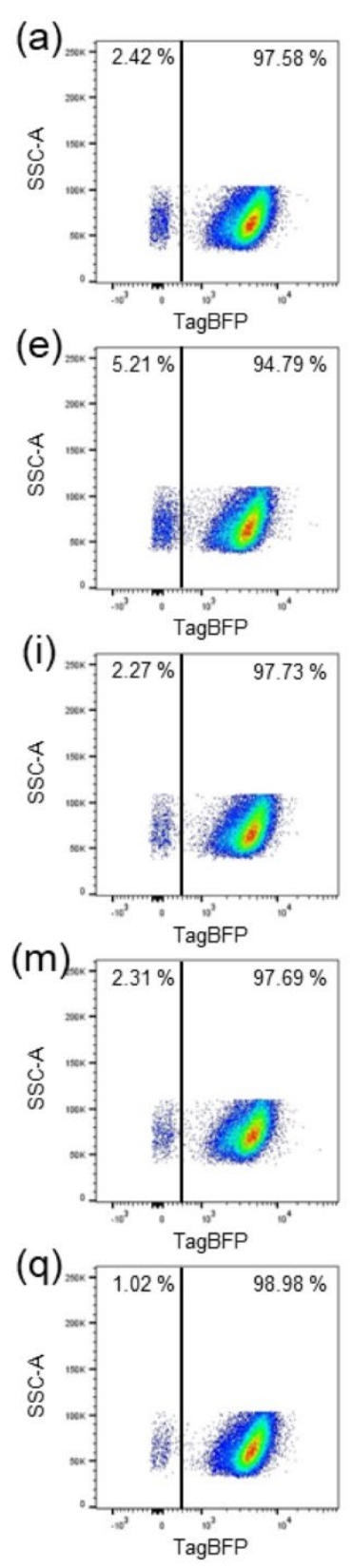
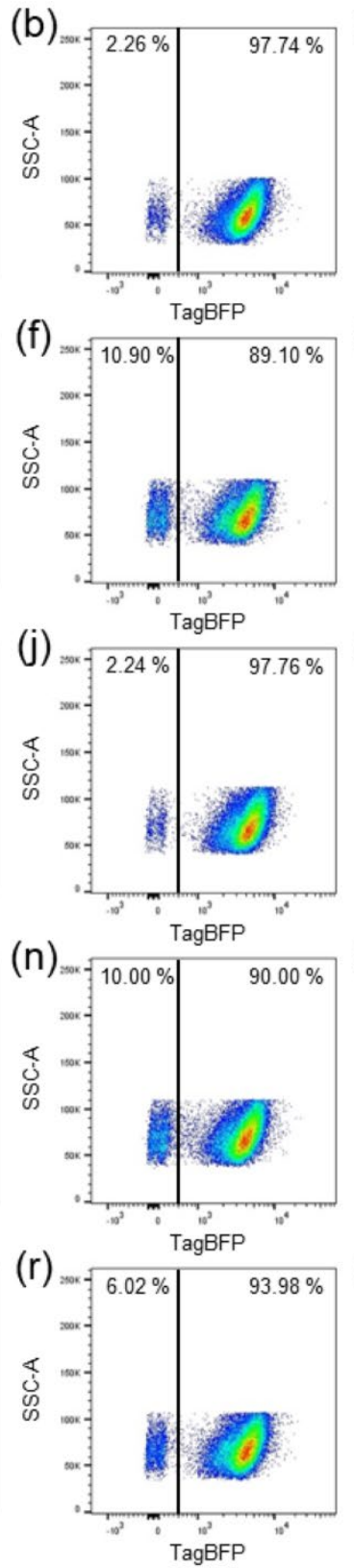
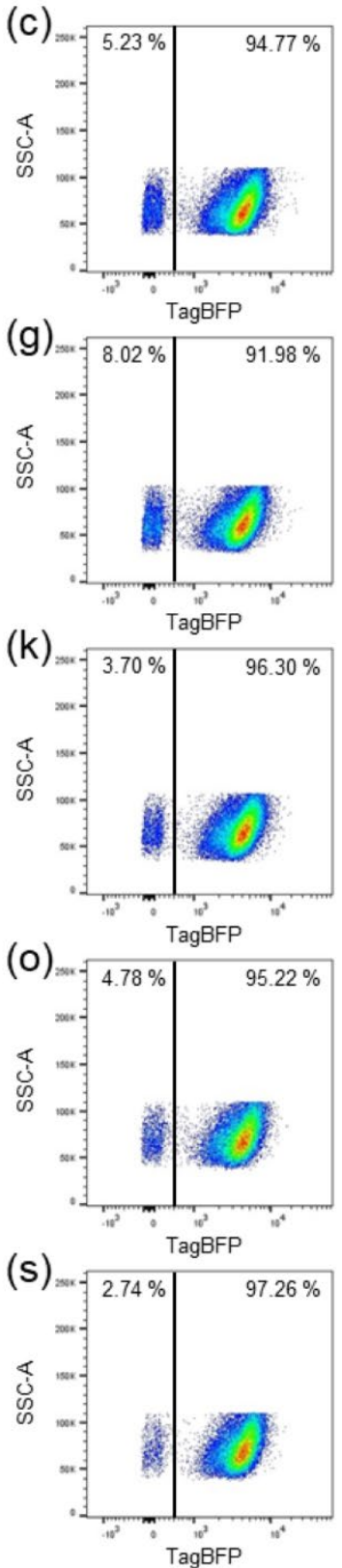
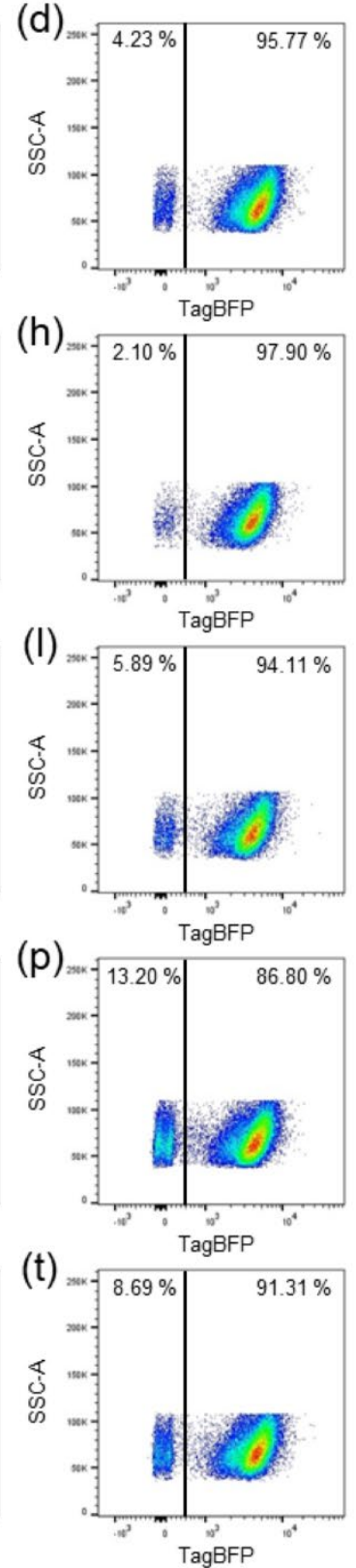

Supporting Figure S6. Representative FACS plots and gates of RMCE in the heterotypic dLP MCL. eGFP attB-donor with (a) control, (b) SV40-N, (c) SV40-C, (d) SV40-N/C, (e) NP-N, (f) NP-C, or (g) NP-N/C NLS Bxb1. Control Bxb1 with (h) control, (i) SV40-5', (j) SV40-3', (k) SV40-5'/3', or (l) NF$\kappa B-5 ' / 3$ ' DTS attB-donor. eGFP donor in (m) control, (n) NLS, (o) DTS, or (p) NLS and DTS used. mAb donor in (q) control, (r) NLS, (s) DTS, or (t) NLS and DTS used. 

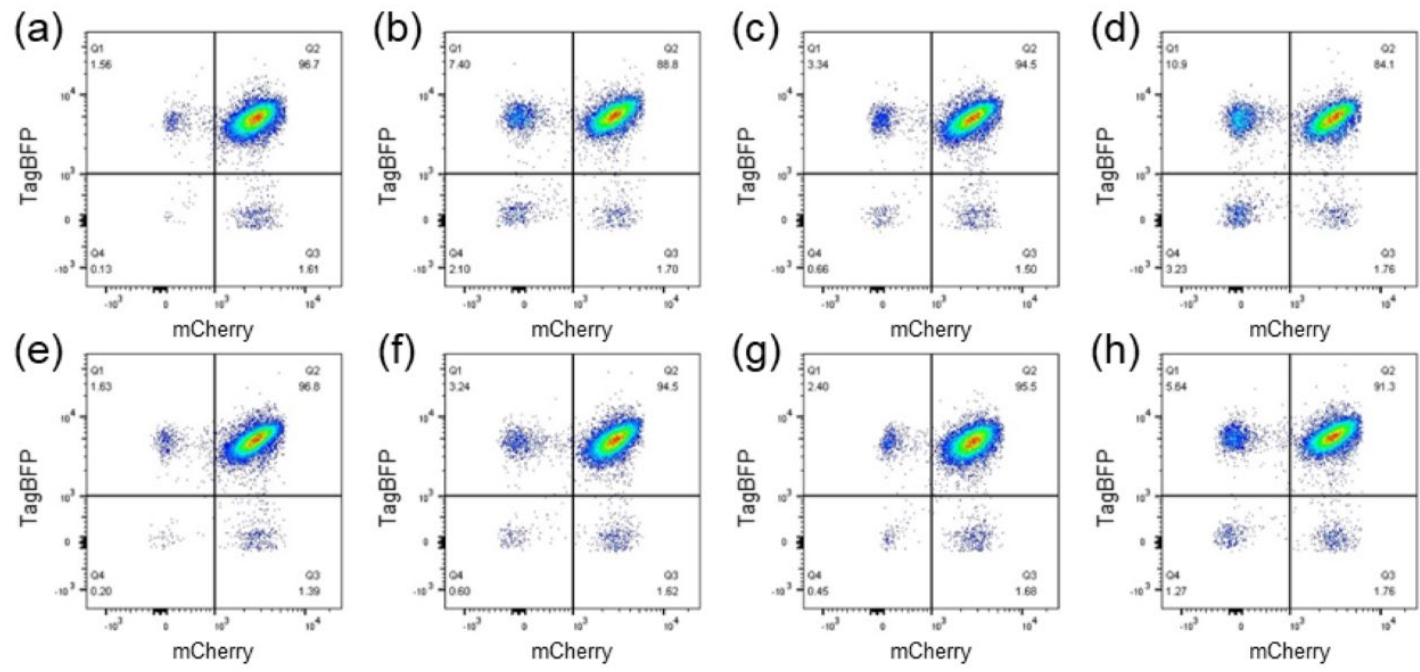

Supporting Figure S7. Representative FACS plots and gates of simultaneous RMCE in the heterotypic dLP MCL. Four plasmids, loxP-donor, Cre recombinase, attB-donor, and Bxb1 integrase, were used for simultaneous RMCE. eGFP donor in (a) control, (b) NLS, (c) DTS, or (d) NLS and DTS used. mAb donor in (e) control, (f) NLS, (g) DTS, or (h) NLS and DTS used. 
(a)

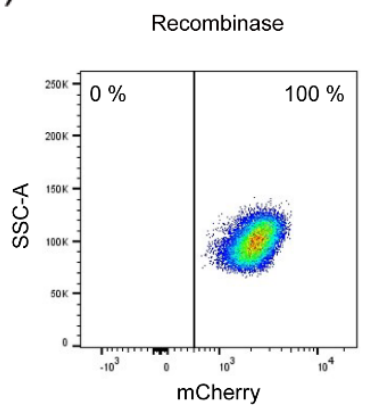

(c)

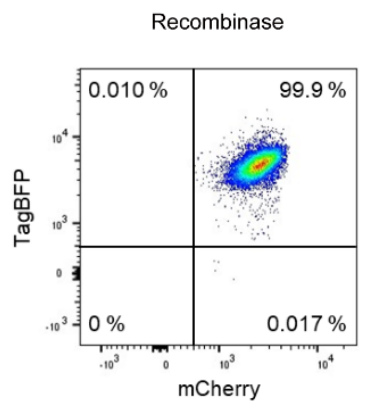

Recombinase + Donor

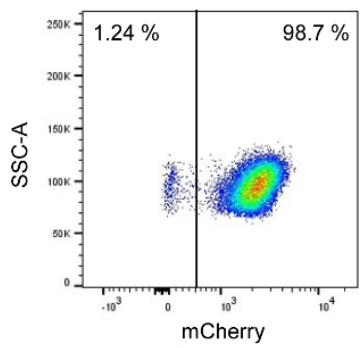

Recombinase + Donor

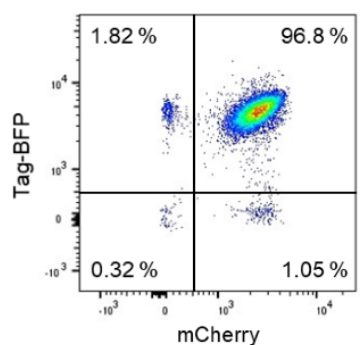

(b)
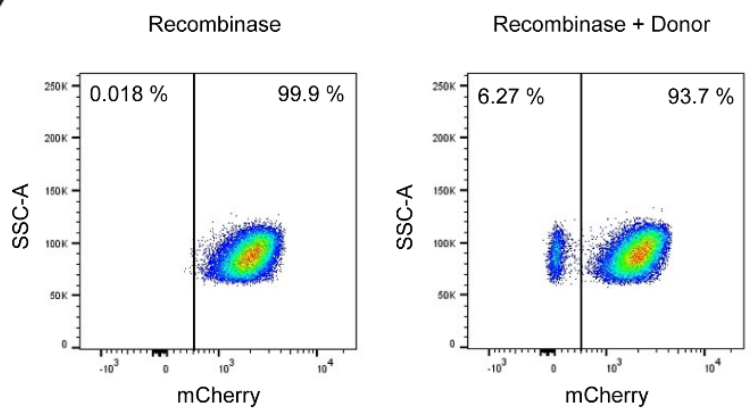

(d)

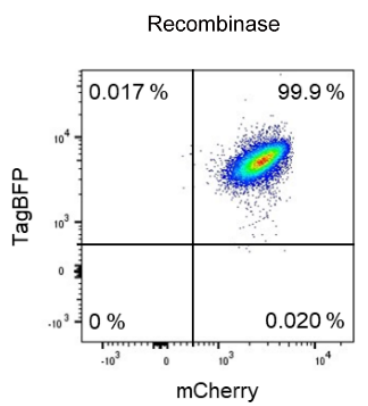

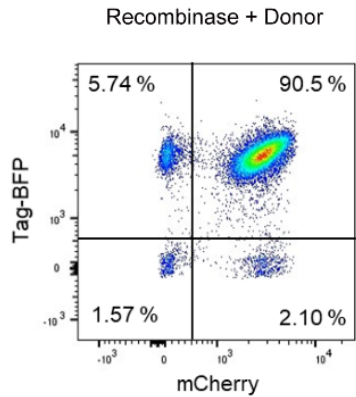

Supporting Figure S8. Generation of recombinant cell pools producing mAbs from single or dual copies. Numbers represent the percentage of cells in which the LP was replaced by mAb genes. Fluorescence of mCherry and TagBFP was measured 8 days post-transfection using flow cytometry (100000 cells). Cre-mediated RMCE was performed in SLP or homotypic dLP MCLs by transfection with Cre recombinase and $\mathrm{mAb}$ donor plasmid. mCherry-negative cells were gated with sLP or homotypic dLP MCLs that were transfected with Cre recombinase alone. (a) Control of sLP MCL. (b) NLS and DTS used in the sLP MCL. (c) Control of homotypic dLP MCL. (d) NLS and DTS used in the homotypic dLP MCL. 
(a)

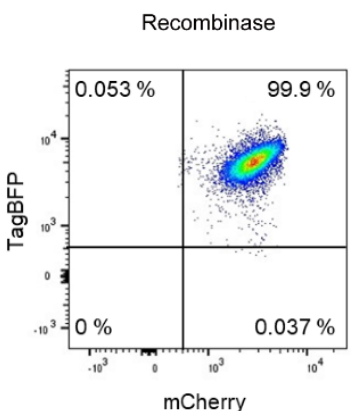

(c)

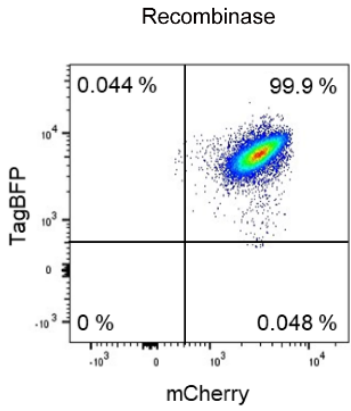

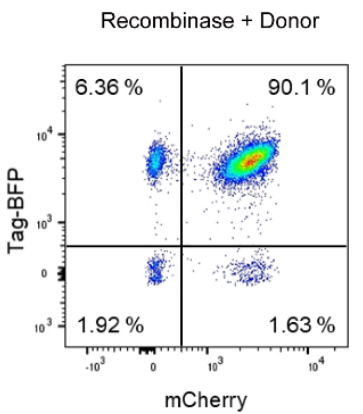

Recombinase + Donor

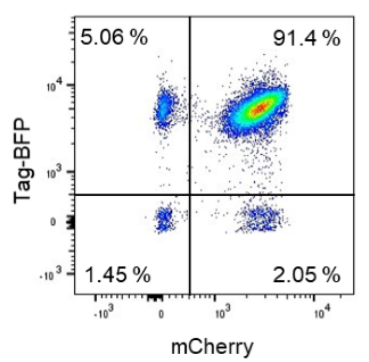

(b)
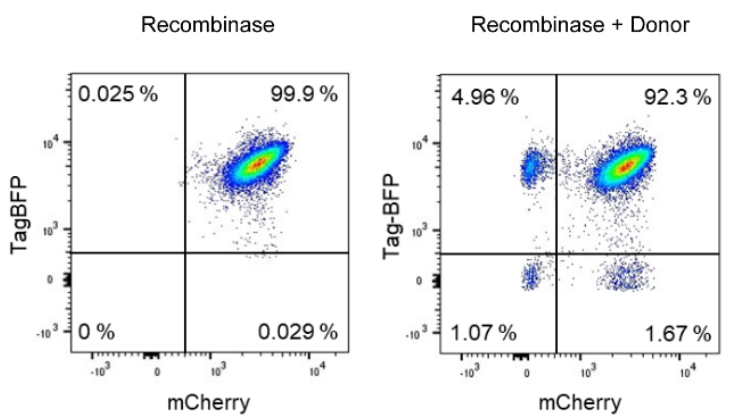

(d)

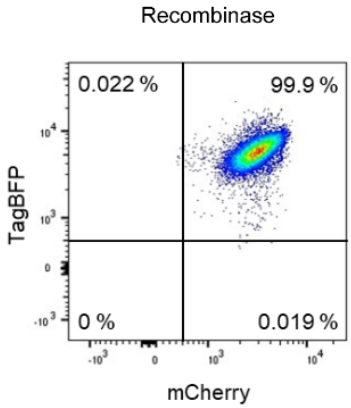

Supporting Figure S9. Simultaneous cassette exchange of $\mathrm{mAb}$ and effector genes related to the UPR pathway. Numbers represent the percentage of cells in which the LP was replaced by mAb and effector genes. Fluorescence of mCherry and TagBFP was measured 8 days post-transfection using flow cytometry (100000 cells). The Cre- and Bxb1-mediated dual-RMCE resulted in mCherrynegative/TagBFP-negative cells, which express mAb genes at the AAVS1 locus and effector genes at the ROSA26 locus. Cell pools expressing mAbs, and (a) eGFP, (b) ATF4, (c) ATF6c, or (d) XBP1s were sorted using heterotypic dLP MCL, which was transfected with Cre recombinase and Bxb1 integrase as a gating control. 


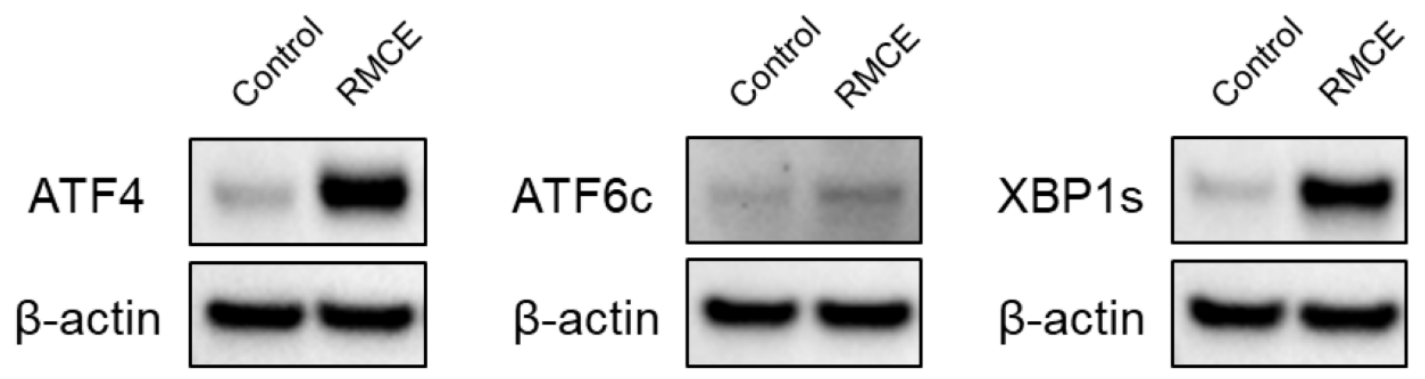

Supporting Figure S10. Protein expression of effector genes related to the UPR pathway, ATF4, $A T F 6 c$, and $X B P 1 s$, in recombinant cell pools. Cells were sorted using MoFlo Astrios EQ (Beckman Coulter, Brea, CA) 8 days post-transfection, and samples were harvested 9 days post-sorting. $\beta$-actin was used as a loading control. 
(a)
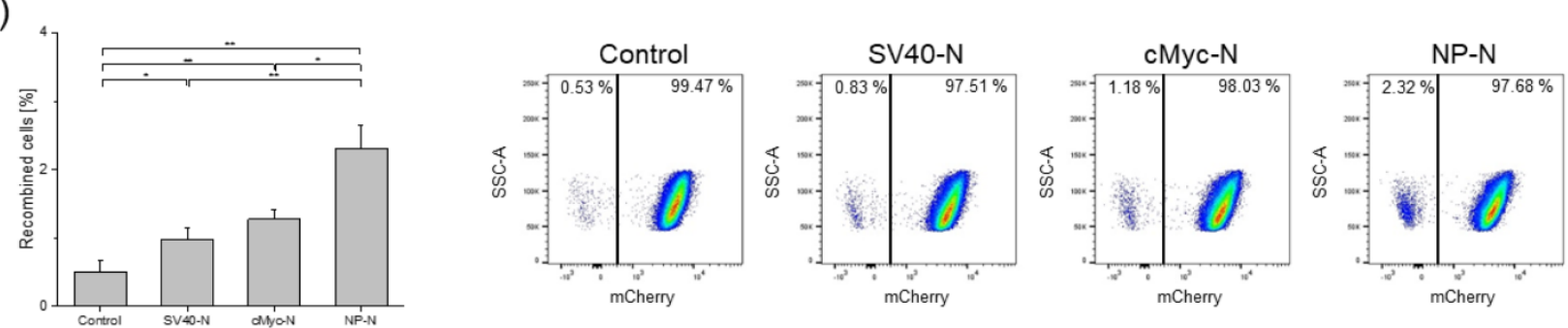

(b)
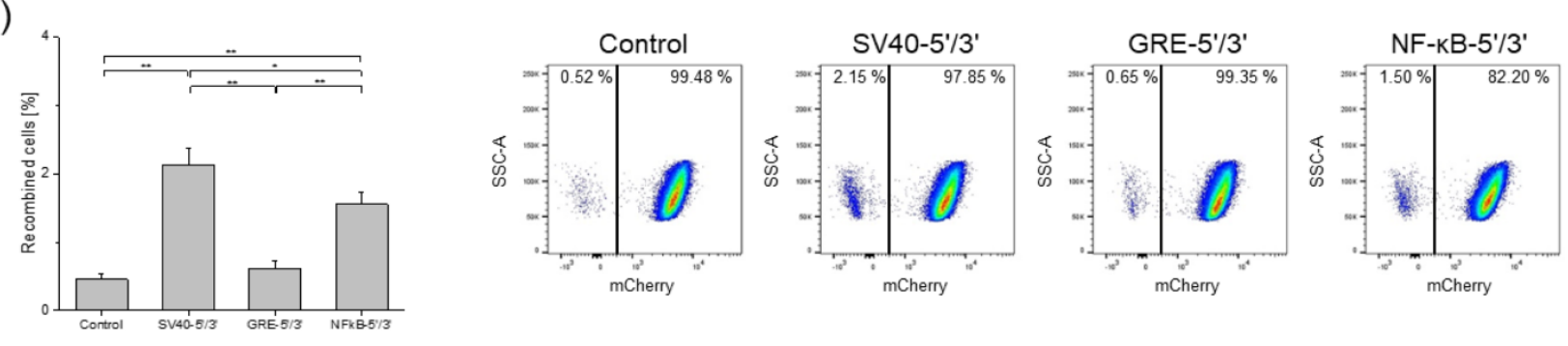

(c)

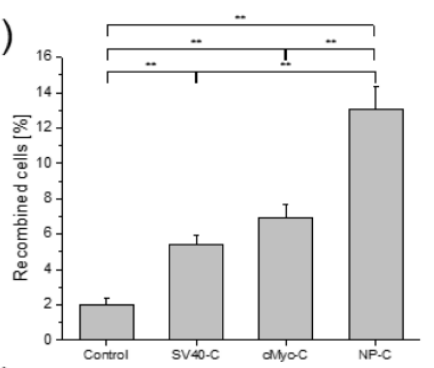

(d)
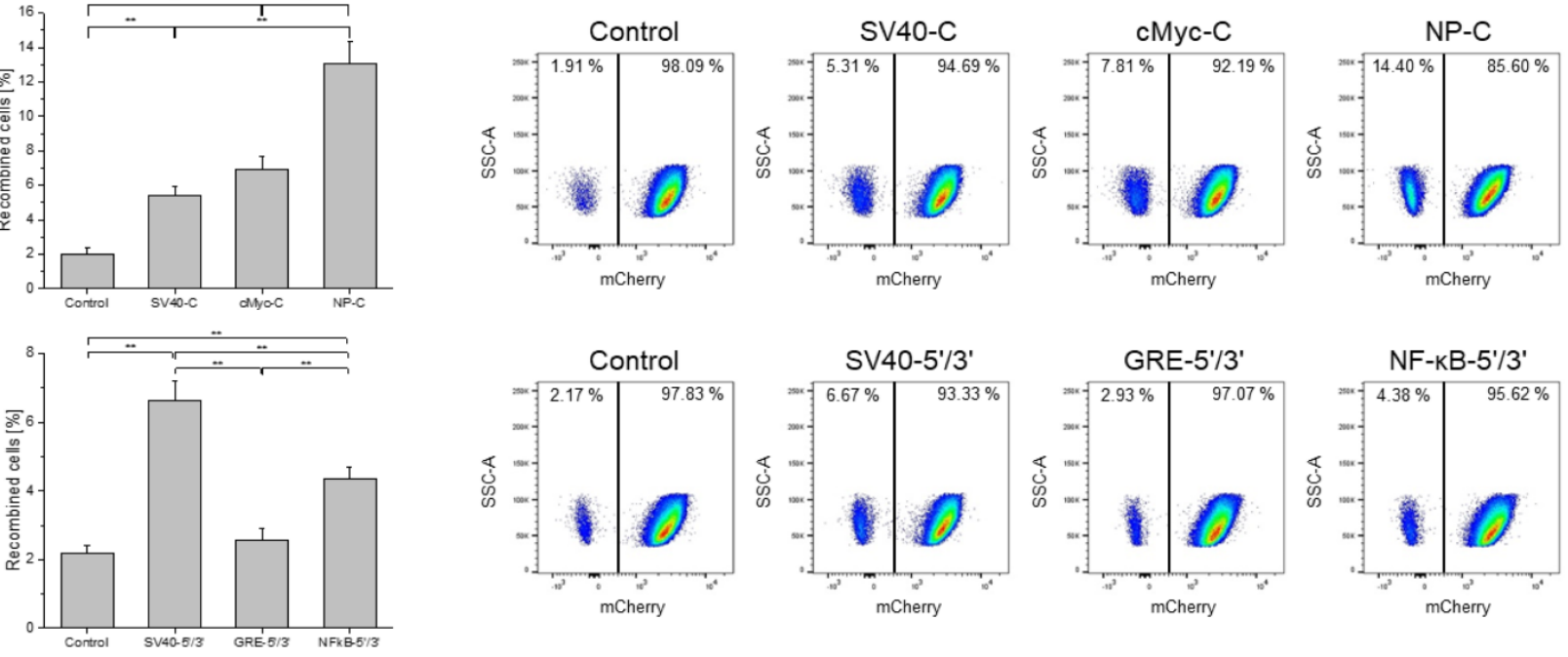

(e)
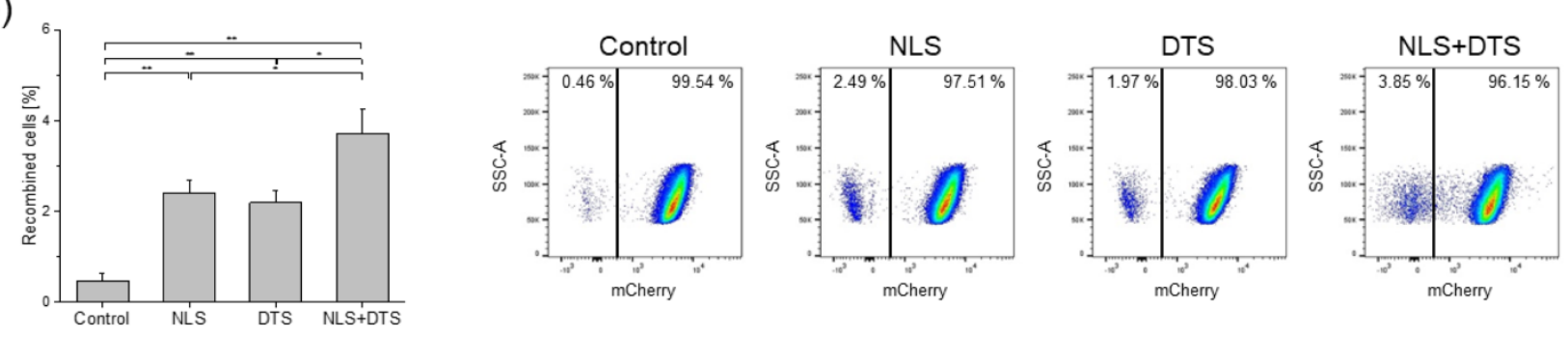

(f)
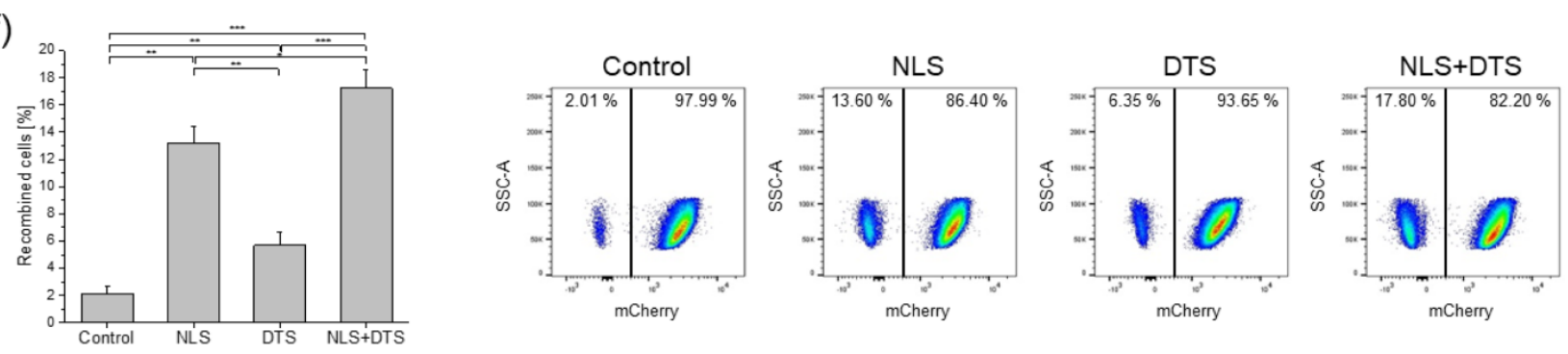
Supporting Figure S11. Improvement of RMCE effciency in CHO cells. RMCE efficiency of eGFP donor in the sLP MCL, harboring a loxP-EF1 $\alpha$-mCherry-lox2272 landing pad, with different types of (a) N-terminal NLS in Cre recombinase and (b) 5'/3' DTS in loxP-donor. RMCE efficiency of eGFP donor in the sLP MCL, harboring a attP-EF1 $\alpha$-mCherry-attP ${ }^{\text {mut }}$ landing pad, with different types of (c) C-terminal NLS in Bxb1 integrase and (d) 5'/3' DTS in attB-donor. (e) RMCE efficiency of eGFP donor in the sLP MCL with a combination of NP N-terminal NLS in Cre recombinase and SV40 5'/3' DTS in loxP-donor. (f) RMCE efficiency of eGFP donor in the sLP MCL with a combination of NP Cterminal NLS in Bxb1 integrase and SV40 5'/3' DTS in attB-donor. Error bars represent standard deviations of three independent experiments. The data were analyzed using a one-way analysis of variance with Tukey's post hoc test, ${ }^{*} \mathrm{p}<0.05,{ }^{* *} \mathrm{p}<0.01,{ }^{* * *} \mathrm{p}<0.001$. 
Supporting Table S1. Plasmid information.

\begin{tabular}{|c|c|}
\hline Plasmid name & Description \\
\hline ROSA26-sgRNA-Cas9 $9^{1}$ & sgRNA targeting ROSA26 locus and Cas9 expression vector \\
\hline ROSA26-LP donor (loxP) & $\begin{array}{c}\text { Donor plasmid targeting ROSA26 locus } \\
\text { (GOI: SA-T2A-ZeoR-BGHpA-loxP-EF1 } \alpha \text {-TagBFP-lox2272-BGHpA) }\end{array}$ \\
\hline ROSA26-LP donor (attP) & $\begin{array}{c}\text { Donor plasmid targeting ROSA26 locus } \\
\text { (GOI: SA-T2A-ZeoR-BGHpA-attP-EF1 } \alpha \text {-TagBFP-attPmut_BGHpA) }\end{array}$ \\
\hline RMCE-eGFP donor (loxP) & $\begin{array}{l}\text { Donor plasmid for RMCE with LP (loxP) } \\
\text { (GOI: loxP-EF1 } \alpha \text {-eGFP-lox2272) }\end{array}$ \\
\hline RMCE-eGFP donor (attB) & $\begin{array}{l}\text { Donor plasmid for RMCE with LP (attP) } \\
\left.\text { (GOI: attB-EF1 } \alpha \text {-eGFP-attB }{ }^{\text {mut }}\right)\end{array}$ \\
\hline RMCE-mAb donor (loxP) & $\begin{array}{l}\text { Donor plasmid for RMCE with LP (loxP) } \\
\text { (GOI: loxP-CMV-LC-BGHpA-CMV-HC-lox } 2272 \text { ) }\end{array}$ \\
\hline RMCE-mAb donor (attB) & $\begin{array}{l}\text { Donor plasmid for RMCE with LP (attP) } \\
\text { (GOI: attB-CMV-LC-BGHpA-CMV-HC-attB }{ }^{\text {mut }} \text { ) }\end{array}$ \\
\hline RMCE-ATF4 donor (attB) & $\begin{array}{l}\text { Donor plasmid for RMCE with LP (attP) } \\
\left.\text { (GOI: attB-EF1 } \alpha \text {-ATF4-attB }{ }^{\text {mut }}\right)\end{array}$ \\
\hline RMCE-ATF6c donor (attB) & $\begin{array}{l}\text { Donor plasmid for RMCE with LP (attP) } \\
\left.\text { (GOI: attB-EF1 } \alpha \text {-ATF6c-attB }{ }^{\text {mut }}\right)\end{array}$ \\
\hline RMCE-XBP1s donor (attB) & $\begin{array}{l}\text { Donor plasmid for RMCE with LP (attP) } \\
\quad\left(\text { GOI: attB-EF } 1 \alpha-X B P 1 s-a^{\text {attBut }}\right)\end{array}$ \\
\hline PSF-CMV-CRE & Cre recombinase expression vector (Sigma-Aldrich) \\
\hline SV40-N-NLS-Cre & Cre recombinase with N-terminal SV40 NLS expression plasmid \\
\hline SV40-C-NLS-Cre & Cre recombinase with C-terminal SV40 NLS expression plasmid \\
\hline SV40-NC-NLS-Cre & Cre recombinase with N- and C-terminal SV40 NLS expression plasmid \\
\hline cMyc-N-NLS-Cre & Cre recombinase with N-terminal cMyc NLS expression plasmid \\
\hline NP-N-NLS-Cre & Cre recombinase with N-terminal NP NLS expression plasmid \\
\hline INCTbiosyn-pUB-HspINTBxb1 & Bxb1 recombinase expression vector (Addgene \# 127519) ${ }^{2}$ \\
\hline SV40-N-NLS-Bxb1 & Bxb1 recombinase with N-terminal SV40 NLS expression plasmid \\
\hline SV40-C-NLS-Bxb1 & Bxb1 recombinase with C-terminal SV40 NLS expression plasmid \\
\hline SV40-NC-NLS-Bxb1 & Bxb1 recombinase with N- and C-terminal SV40 NLS expression plasmid \\
\hline NP-N-NLS-Bxb1 & Bxb1 recombinase with N-terminal NP NLS expression plasmid \\
\hline NP-C-NLS-Bxb1 & Bxb1 recombinase with C-terminal NP NLS expression plasmid \\
\hline
\end{tabular}




\begin{tabular}{|c|c|}
\hline NP-NC-NLS-Bxb1 & Bxb1 recombinase with N- and C-terminal NP NLS expression plasmid \\
\hline SV40-5'-DTS-eGFP (loxP) & $\begin{array}{l}\text { Donor plasmid for RMCE with LP (loxP) } \\
\text { (GOI: SV40 DTS-loxP-EF1 } \alpha \text {-eGFP-lox2272) }\end{array}$ \\
\hline SV40-3'-DTS-eGFP (loxP) & $\begin{array}{l}\text { Donor plasmid for RMCE with LP (loxP) } \\
\text { (GOI: loxP-EF1 } \alpha \text {-eGFP-lox2272-SV40 DTS) }\end{array}$ \\
\hline SV40-5'/3'-DTS-eGFP (loxP) & $\begin{array}{l}\text { Donor plasmid for RMCE with LP (loxP) } \\
\text { (GOI: SV40 DTS-loxP-EF1 } \alpha \text {-eGFP-lox2272-SV40 DTS) }\end{array}$ \\
\hline GRE-5'/3'-DTS-eGFP (loxP) & $\begin{array}{l}\text { Donor plasmid for RMCE with LP (loxP) } \\
\text { (GOI: GRE DTS-loxP-EF1 } \alpha \text {-eGFP-lox2272-GRE DTS) }\end{array}$ \\
\hline NF- $\kappa B-5 ' / 3 '-D T S-e G F P(l o x P)$ & 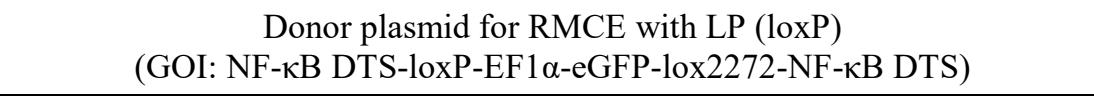 \\
\hline SV40-5'-DTS-eGFP (attB) & $\begin{array}{l}\text { Donor plasmid for RMCE with LP (attP) } \\
\text { (GOI: SV40 DTS-attB-EF1 } \alpha \text {-eGFP-attB }{ }^{\text {mut }} \text { ) }\end{array}$ \\
\hline SV40-3'-DTS-eGFP (attB) & $\begin{array}{l}\text { Donor plasmid for RMCE with LP (attP) } \\
\text { (GOI: attB-EF1 } \alpha \text {-eGFP-attB }{ }^{\text {mut }} \text {-SV40 DTS) }\end{array}$ \\
\hline SV40-5'/3'-DTS-eGFP (attB) & $\begin{array}{l}\text { Donor plasmid for RMCE with LP (attP) } \\
\text { (GOI: SV40 DTS-attB-EF1 } \alpha \text {-eGFP-attB }{ }^{\text {mut }} \text {-SV40 DTS) }\end{array}$ \\
\hline NF-кB-5'/3'-DTS-eGFP (attB) & 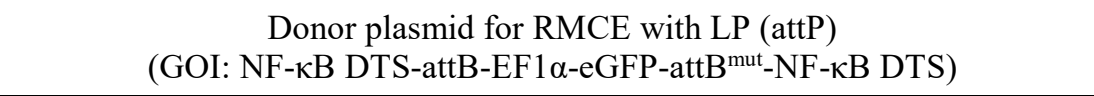 \\
\hline NF- $\kappa B-5 ' / 3^{\prime}-\mathrm{DTS}-\mathrm{mAb}(\mathrm{loxP})$ & 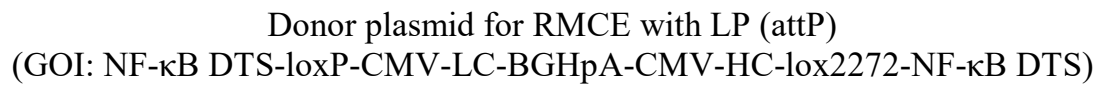 \\
\hline NF- $\kappa B-5^{\prime} / 3^{\prime}-\mathrm{DTS}-\mathrm{mAb}(\mathrm{attB})$ & 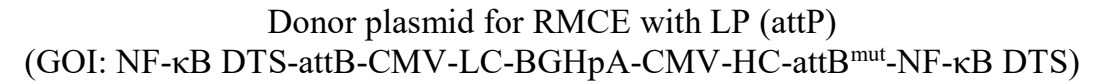 \\
\hline
\end{tabular}

\begin{tabular}{|c|c|}
\hline $\begin{array}{c}\text { Plasmid name } \\
\text { (PCR template) }\end{array}$ & Element \\
\hline pcDNA3.1/Zeo(+) & ZeoR (Life Technologies) \\
\hline PL0626 $6^{3}$ & TagBFP \\
\hline pAAVS1-TLR targeting vector & Backbone of LP donor plasmid (Addgene plasmid \#64215) \\
\hline RMCE eGFP donor plasmid ${ }^{5}$ & EF1 $\alpha$ promoter and eGFP gene \\
\hline RMCE EPO donor plasmid & Backbone of RMCE donor plasmid \\
\hline PSF-CMV-CRE & CMV promoter, Cre gene, SV40pA, and Backbone of recombinase plasmid \\
\hline INCTbiosyn-pUB-HspINTBxb1 ${ }^{2}$ & Bxb1 gene \\
\hline
\end{tabular}

LP, landing pad; GOI, gene of interest; SA, splicing acceptor; mAb, monoclonal antibody; LC, light chain; HC, heavy chain; NLS, nuclear localization signal; NP, nucleoplasmin; DTS, DNA nuclear-targeting sequence; GRE, glucocorticoid responsive element 
Supporting Table S2. Primer sequences.

\begin{tabular}{|c|c|c|}
\hline Primer name & Description & Sequence $\left(5^{\prime}-3^{\prime}\right)$ \\
\hline SA-T2A-ZeoR_fwd & $\begin{array}{l}\text { USER primer for LP donor (loxP) } \\
\text { plasmid }\end{array}$ & $\begin{array}{l}\text { AAGCAGCGUAAGCTTCTGACCT } \\
\text { CTTCTC }\end{array}$ \\
\hline SA-T2A-ZeoR_rev & $\begin{array}{l}\text { USER primer for LP donor (loxP) } \\
\text { plasmid }\end{array}$ & $\begin{array}{l}\text { ATAGGCTTUCCATAGAGCCCACC } \\
\text { GCATC }\end{array}$ \\
\hline loxP-EF1 $\alpha$-TagBFP-lox2272_fwd & $\begin{array}{l}\text { USER primer for LP donor (loxP) } \\
\text { plasmid }\end{array}$ & $\begin{array}{l}\text { AAAGCCTAUATAACTTCGTATAG } \\
\text { CATAC }\end{array}$ \\
\hline loxP-EF1 $\alpha$-TagBFP-lox2272_rev & $\begin{array}{l}\text { USER primer for LP donor (loxP) } \\
\text { plasmid }\end{array}$ & $\begin{array}{l}\text { ATGACGTCUATAACTTCGTATAA } \\
\text { AGTATCCTATACGAAGTTATTTA } \\
\text { ATTAAGCTTGTGCCCCAG }\end{array}$ \\
\hline SA-T2A-ZeoR_fwd & $\begin{array}{l}\text { USER primer for LP donor (attP) } \\
\text { plasmid }\end{array}$ & $\begin{array}{l}\text { AAGCAGCGUAAGCTTCTGACCT } \\
\text { CTTCTC }\end{array}$ \\
\hline SA-T2A-ZeoR-attP_rev & $\begin{array}{l}\text { USER primer for LP donor (attP) } \\
\text { plasmid }\end{array}$ & $\begin{array}{l}\text { ATAGGCTTUTGGGTTTGTACCGT } \\
\text { ACACCACTGAGACCGCGGTGGT } \\
\text { TGACCAGACAAACCACCCATAG } \\
\text { AGCCCACCGCATC }\end{array}$ \\
\hline attP-EF1 $\alpha$-TagBFP-attPmut ${ }_{-}$fwd & $\begin{array}{l}\text { USER primer for LP donor (attP) } \\
\text { plasmid }\end{array}$ & $\begin{array}{l}\text { AAAGCCTAUGTGAGGCTCCGGT } \\
\text { GCCCGTC }\end{array}$ \\
\hline attP-EF1 $\alpha$-TagBFP-attPmut rev & $\begin{array}{l}\text { USER primer for LP donor (attP) } \\
\text { plasmid }\end{array}$ & $\begin{array}{l}\text { ATGACGTCUTGGGTTTGTACCGT } \\
\text { ACACCACTGAGTCCGCGGTGGTT } \\
\text { GACCAGACAAACCACTTAATTA } \\
\text { AGCTTGTGCCCCAG }\end{array}$ \\
\hline ATF4_fwd & $\begin{array}{l}\text { USER primer for ATF4 donor } \\
\text { plasmid }\end{array}$ & $\begin{array}{l}\text { AAGCAGCGUGCCACCATGACCG } \\
\text { AAATGAG }\end{array}$ \\
\hline ATF4_rev & $\begin{array}{l}\text { USER primer for ATF4 donor } \\
\text { plasmid }\end{array}$ & $\begin{array}{l}\text { ACGCAAGUCTAGGGGACCCTTTT } \\
\text { CTTCC }\end{array}$ \\
\hline ATF6c_fwd & $\begin{array}{l}\text { USER primer for ATF6c donor } \\
\text { plasmid }\end{array}$ & $\begin{array}{l}\text { AAGCAGCGUGCCACCATGGGGG } \\
\text { AGCCGGC }\end{array}$ \\
\hline ATF6c_rev & $\begin{array}{l}\text { USER primer for ATF6c donor } \\
\text { plasmid }\end{array}$ & $\begin{array}{l}\text { ACGCAAGUCTAACTAGGGACTT } \\
\text { TAAGCC }\end{array}$ \\
\hline XBP1s_fwd & $\begin{array}{l}\text { USER primer for XBP1s donor } \\
\text { plasmid }\end{array}$ & $\begin{array}{l}\text { AAGCAGCGUGCCACCATGGTGG } \\
\text { TGGTGGC }\end{array}$ \\
\hline XBP1s_rev & $\begin{array}{l}\text { USER primer for XBP1s donor } \\
\text { plasmid }\end{array}$ & $\begin{array}{l}\text { ACGCAAGUTTAGACACTAATCA } \\
\text { GCTGGG }\end{array}$ \\
\hline SV40-N-NLS-Cre_fwd & $\begin{array}{l}\text { USER primer for SV40-N-NLS- } \\
\text { Cre plasmid }\end{array}$ & $\begin{array}{l}\text { AAAGCCTAUGCCACCATGGCCC } \\
\text { CAAAGAAGAAGCGGAAGGTCGG } \\
\text { AAGCATGTCCAATTTACTGACCG }\end{array}$ \\
\hline SV40-N-NLS-Cre_rev & $\begin{array}{l}\text { USER primer for SV40-N-NLS- } \\
\text { Cre plasmid }\end{array}$ & $\begin{array}{l}\text { ACGCTGCTUCTAGTCGCCATCTT } \\
\text { CCAGCAG }\end{array}$ \\
\hline SV40-C-NLS-Cre_fwd & $\begin{array}{l}\text { USER primer for SV40-C-NLS- } \\
\text { Cre plasmid }\end{array}$ & $\begin{array}{l}\text { AAAGCCTAUGCCACCATGGCCA } \\
\text { TGTCCAATTTACTGACCG }\end{array}$ \\
\hline SV40-C-NLS-Cre_rev & $\begin{array}{l}\text { USER primer for SV40-C-NLS- } \\
\text { Cre plasmid }\end{array}$ & $\begin{array}{l}\text { ACGCTGCTUTTAACTGCCTACCT } \\
\text { TCCTCTTCTTCTTGGGGCTGCCG } \\
\text { TCGCCATCTTCCAGCAGGC }\end{array}$ \\
\hline SV40-NC-NLS-Cre_fwd & $\begin{array}{l}\text { USER primer for SV40-NC-NLS- } \\
\text { Cre plasmid }\end{array}$ & $\begin{array}{l}\text { AAAGCCTAUGCCACCATGGCCC } \\
\text { CAAAGAAGAAGCGGAAGGTCGG } \\
\text { AAGCATGTCCAATTTACTGACCG }\end{array}$ \\
\hline SV40-NC-NLS-Cre_rev & $\begin{array}{l}\text { USER primer for SV40-NC-NLS- } \\
\text { Cre plasmid }\end{array}$ & $\begin{array}{l}\text { ACGCTGCTUTTAACTGCCTACCT } \\
\text { TCCTCTTCTTCTTGGGGCTGCCG } \\
\text { TCGCCATCTTCCAGCAGGC }\end{array}$ \\
\hline cMyc-N-NLS-Cre_fwd & $\begin{array}{l}\text { USER primer for cMyc-N-NLS- } \\
\text { Cre plasmid }\end{array}$ & $\begin{array}{l}\text { AAAGCCTAUGCCACCATGGCCC } \\
\text { CTGCTGCCAAACGCGTTAAACTA } \\
\text { GACATGTCCAATTTACTGACCG }\end{array}$ \\
\hline
\end{tabular}




\begin{tabular}{|c|c|c|}
\hline cMyc-N-NLS-Cre_rev & $\begin{array}{l}\text { USER primer for cMyc-N-NLS- } \\
\text { Cre plasmid }\end{array}$ & $\begin{array}{l}\text { ACGCTGCTUCTAGTCGCCATCTT } \\
\text { CCAGCAG }\end{array}$ \\
\hline NP-N-NLS-Cre_fwd & $\begin{array}{l}\text { USER primer for NP-N-NLS- } \\
\text { Cre plasmid }\end{array}$ & $\begin{array}{l}\text { AAAGCCTAUGCCACCATGGCCA } \\
\text { AAAGGCCGGCGGCCACGAAAAA } \\
\text { GGCCGGCCAGGCAAAAAAGAAA } \\
\text { AAGGGAAGCATGTCCAATTTACT } \\
\text { GACCG }\end{array}$ \\
\hline NP-N-NLS-Cre_rev & $\begin{array}{l}\text { USER primer for NP-N-NLS- } \\
\text { Cre plasmid }\end{array}$ & $\begin{array}{l}\text { ACGCTGCTUCTAGTCGCCATCTT } \\
\text { CCAGCAG }\end{array}$ \\
\hline SV40-N-NLS-Bxb1_fwd & $\begin{array}{l}\text { USER primer for SV40-N-NLS- } \\
\text { Bxb1 plasmid }\end{array}$ & $\begin{array}{l}\text { AAAGCCTAUGCCACCATGGCCC } \\
\text { CAAAGAAGAAGCGGAAGGTCGG } \\
\text { AAGCATGCGGGCACTGGTGGTA } \\
\text { ATTAG }\end{array}$ \\
\hline SV40-N-NLS-Bxb1_rev & $\begin{array}{l}\text { USER primer for SV40-N-NLS- } \\
\text { Bxb1 plasmid }\end{array}$ & $\begin{array}{l}\text { ACGCTGCTUCTAAGACATCCCTG } \\
\text { TATGCAG }\end{array}$ \\
\hline SV40-C-NLS-Bxb1_fwd & $\begin{array}{l}\text { USER primer for SV40-C-NLS- } \\
\text { Bxb1 plasmid }\end{array}$ & $\begin{array}{l}\text { AAAGCCTAUGCCACCATGGCCA } \\
\text { TGCGGGCACTGGTGGTAATTAG }\end{array}$ \\
\hline SV40-C-NLS-Bxb1_rev & $\begin{array}{l}\text { USER primer for SV40-C-NLS- } \\
\text { Bxb1 plasmid }\end{array}$ & $\begin{array}{l}\text { ACGCTGCTUTTAACTGCCTACCT } \\
\text { TCCTCTTCTTCTTGGGGCTGCCA } \\
\text { GACATCCCTGTATGCAGTC }\end{array}$ \\
\hline SV40-NC-NLS-Bxb1_fwd & $\begin{array}{l}\text { USER primer for SV40-NC-NLS- } \\
\text { Bxb1 plasmid }\end{array}$ & $\begin{array}{l}\text { AAAGCCTAUGCCACCATGGCCC } \\
\text { CAAAGAAGAAGCGGAAGGTCGG } \\
\text { AAGCATGCGGGCACTGGTGGTA } \\
\text { ATTAG }\end{array}$ \\
\hline SV40-NC-NLS-Bxb1_rev & $\begin{array}{l}\text { USER primer for SV40-NC-NLS- } \\
\text { Bxb1 plasmid }\end{array}$ & $\begin{array}{l}\text { ACGCTGCTUTTAACTGCCTACCT } \\
\text { TCCTCTTCTTCTTGGGGCTGCCA } \\
\text { GACATCCCTGTATGCAGTC }\end{array}$ \\
\hline NP-N-NLS-Bxb1_fwd & $\begin{array}{l}\text { USER primer for NP-N-NLS- } \\
\text { Bxb1 plasmid }\end{array}$ & $\begin{array}{l}\text { AAAGCCTAUGCCACCATGGCCA } \\
\text { AAAGGCCGGCGGCCACGAAAAA } \\
\text { GGCCGGCCAGGCAAAAAAGAAA } \\
\text { AAGGGAAGCATGCGGGCACTGG } \\
\text { TGGTAATTAG }\end{array}$ \\
\hline NP-N-NLS-Bxb1_rev & $\begin{array}{l}\text { USER primer for NP-N-NLS- } \\
\text { Bxb1 plasmid }\end{array}$ & $\begin{array}{l}\text { ACGCTGCTUCTAAGACATCCCTG } \\
\text { TATGCAG }\end{array}$ \\
\hline NP-C-NLS-Bxb1_fwd & $\begin{array}{l}\text { USER primer for NP-C-NLS- } \\
\text { Bxb1 plasmid }\end{array}$ & $\begin{array}{l}\text { AAAGCCTAUGCCACCATGGCCA } \\
\text { TGCGGGCACTGGTGGTAATTAG }\end{array}$ \\
\hline NP-C-NLS-Bxb1_rev & $\begin{array}{l}\text { USER primer for NP-C-NLS- } \\
\text { Bxb1 plasmid }\end{array}$ & $\begin{array}{l}\text { ACGCTGCTUTTAACTGCCCTTTT } \\
\text { TCTTTTTTGCCTGGCCGGCCTTTT } \\
\text { TCGTGGCCGCCGGCCTTTTGCTG } \\
\text { CCAGACATCCCTGTATGCAGTC }\end{array}$ \\
\hline NP-NC-NLS-Bxb1_fwd & $\begin{array}{l}\text { USER primer for NP-NC-NLS- } \\
\text { Bxb1 plasmid }\end{array}$ & $\begin{array}{l}\text { AAAGCCTAUGCCACCATGGCCA } \\
\text { AAAGGCCGGCGGCCACGAAAAA } \\
\text { GGCCGGCCAGGCAAAAAAGAAA } \\
\text { AAGGGAAGCATGCGGGCACTGG } \\
\text { TGGTAATTAG }\end{array}$ \\
\hline NP-NC-NLS-Bxb1_rev & $\begin{array}{l}\text { USER primer for NP-NC-NLS- } \\
\text { Bxb1 plasmid }\end{array}$ & $\begin{array}{l}\text { ACGCTGCTUTTAACTGCCCTTTT } \\
\text { TCTTTTTTGCCTGGCCGGCCTTTT } \\
\text { TCGTGGCCGCCGGCCTTTTGCTG } \\
\text { CCAGACATCCCTGTATGCAGTC }\end{array}$ \\
\hline SV40-5'-DTS-eGFP_fwd & $\begin{array}{l}\text { USER primer for SV40-5'-DTS- } \\
\text { eGFP donor plasmid }\end{array}$ & $\begin{array}{l}\text { AGTCGGTGUGGTGTGGAAAGTC } \\
\text { CCCAGGCTCCCCAGCAGGCAGA } \\
\text { AGTATGCAAAGCATGCATCTCA } \\
\text { ATTAGTCAGCAACCACGATGGT } \\
\text { AGTGTGGGGACTC }\end{array}$ \\
\hline SV40-5'-DTS-eGFP_rev & $\begin{array}{l}\text { USER primer for SV40-5'-DTS- } \\
\text { eGFP donor plasmid }\end{array}$ & $\begin{array}{l}\text { ACGCAAGUGTGTCGCCCTTATTC } \\
\text { GACTC }\end{array}$ \\
\hline
\end{tabular}




\begin{tabular}{|c|c|c|}
\hline SV40-3'-DTS-eGFP_fwd & $\begin{array}{l}\text { USER primer for SV40-3'-DTS- } \\
\text { eGFP donor plasmid }\end{array}$ & $\begin{array}{l}\text { AGTCGGTGUCGATGGTAGTGTG } \\
\text { GGGACTC }\end{array}$ \\
\hline SV40-3'-DTS-eGFP_rev & $\begin{array}{l}\text { USER primer for SV40-3'-DTS- } \\
\text { eGFP donor plasmid }\end{array}$ & $\begin{array}{l}\text { ACGCAAGUTGGTTGCTGACTAAT } \\
\text { TGAGATGCATGCTTTGCATACTT } \\
\text { CTGCCTGCTGGGGAGCCTGGGG } \\
\text { ACTTTCCACACCGTGTCGCCCTT } \\
\text { ATTCGACTC }\end{array}$ \\
\hline SV40-5'/3'-DTS-eGFP_fwd & $\begin{array}{l}\text { USER primer for SV40-5'/3'- } \\
\text { DTS-eGFP donor plasmid }\end{array}$ & $\begin{array}{l}\text { AGTCGGTGUGGTGTGGAAAGTC } \\
\text { CCCAGGCTCCCCAGCAGGCAGA } \\
\text { AGTATGCAAAGCATGCATCTCA } \\
\text { ATTAGTCAGCAACCACGATGGT } \\
\text { AGTGTGGGGACTC }\end{array}$ \\
\hline SV40-5'/3'-DTS-eGFP_rev & $\begin{array}{l}\text { USER primer for SV40-5'/3'- } \\
\text { DTS-eGFP donor plasmid }\end{array}$ & $\begin{array}{l}\text { ACGCAAGUTGGTTGCTGACTAAT } \\
\text { TGAGATGCATGCTTTGCATACTT } \\
\text { CTGCCTGCTGGGGAGCCTGGGG } \\
\text { ACTTTCCACACCGTGTCGCCCTT } \\
\text { ATTCGACTC }\end{array}$ \\
\hline GRE-5'/3'-DTS-eGFP_fwd & $\begin{array}{l}\text { USER primer for GRE-5'/3'-DTS- } \\
\text { eGFP donor plasmid }\end{array}$ & $\begin{array}{l}\text { AGTCGGTGUACGGGTGGTACAG } \\
\text { AATGTTCTTTTGGCGTCGACACG } \\
\text { GGTGGTACAGAATGTTCTTTTGG } \\
\text { CCGATGGTAGTGTGGGGACTC }\end{array}$ \\
\hline GRE-5'/3'-DTS-eGFP_rev & $\begin{array}{l}\text { USER primer for GRE-5'/3'-DTS- } \\
\text { eGFP donor plasmid }\end{array}$ & $\begin{array}{l}\text { ACGCAAGUGCCAAAAGAACATT } \\
\text { CTGTACCACCCGTGTCGACGCCA } \\
\text { AAAGAACATTCTGTACCACCCGT } \\
\text { CCTTATTCGACTCACTACGC }\end{array}$ \\
\hline NF- $\kappa B-5 ' / 3 '-D T S-e G F P \_f w d$ & $\begin{array}{l}\text { USER primer for NF- } \kappa \text { B-5'/3'- } \\
\text { DTS-eGFP donor plasmid }\end{array}$ & $\begin{array}{l}\text { AGTCGGTGUCTGGGGACTTTCCA } \\
\text { GCTGGGGACTTTCCAGCTGGGG } \\
\text { ACTTTCCAGCTGGGGACTTTCCA } \\
\text { GGCGATGGTAGTGTGGGGACTC }\end{array}$ \\
\hline NF-кB-5'/3'-DTS-eGFP_rev & $\begin{array}{l}\text { USER primer for NF-кB-5'/3'- } \\
\text { DTS-eGFP donor plasmid }\end{array}$ & $\begin{array}{l}\text { ACGCAAGUCCTGGAAAGTCCCC } \\
\text { AGCTGGAAAGTCCCCAGCTGGA } \\
\text { AAGTCCCCAGCTGGAAAGTCCC } \\
\text { CAGCCTTATTCGACTCACTACGC }\end{array}$ \\
\hline CMV_fwd & $\begin{array}{l}\text { USER primer for Cre and Bxb1 } \\
\text { recombinase plasmid }\end{array}$ & $\begin{array}{l}\text { AGTCGGTGUTGCTGATCGAGTGT } \\
\text { AGCCAG }\end{array}$ \\
\hline CMV_rev & $\begin{array}{l}\text { USER primer for Cre and Bxb1 } \\
\text { recombinase plasmid }\end{array}$ & $\begin{array}{l}\text { ATAGGCTTUGATCTGACGGTTCA } \\
\text { CTAAAC }\end{array}$ \\
\hline SV40pA_fwd & $\begin{array}{l}\text { USER primer for Cre and Bxb1 } \\
\text { recombinase plasmid }\end{array}$ & $\begin{array}{l}\text { AAGCAGCGUCTGACTGAGATAC } \\
\text { AGCGTAC }\end{array}$ \\
\hline SV40pA_rev & $\begin{array}{l}\text { USER primer for Cre and Bxb1 } \\
\text { recombinase plasmid }\end{array}$ & $\begin{array}{l}\text { ACGCAAGUTAGAGATGGGCCAA } \\
\text { TACCAC }\end{array}$ \\
\hline Backbone-Recombinase_fwd & $\begin{array}{l}\text { USER primer for Cre and Bxb1 } \\
\text { recombinase plasmid }\end{array}$ & $\begin{array}{l}\text { ACTTGCGUGGGCCGGATTGCTAT } \\
\text { CTACC }\end{array}$ \\
\hline Backbone-Recombinase_rev & $\begin{array}{l}\text { USER primer for Cre and Bxb1 } \\
\text { recombinase plasmid }\end{array}$ & $\begin{array}{l}\text { ACACCGACUTCGCTATCCATCGA } \\
\text { AGATGG }\end{array}$ \\
\hline Backbone-NF- $\kappa$ B_fwd & $\begin{array}{l}\text { USER primer for NF- } \mathrm{NB}-5^{\prime} / 3^{\prime}- \\
\text { DTS donor plasmid }\end{array}$ & $\begin{array}{l}\text { ACTTGCGUCTGGGGACTTTCCAG } \\
\text { CTGGGGACTTTCCAGCTGGGGAC } \\
\text { TTTCCAGCTGGGGACTTTCCAGG } \\
\text { AGTGAGTCGAATAAGGGCGAC }\end{array}$ \\
\hline Backbone-NF- $\kappa$ B_rev & $\begin{array}{l}\text { USER primer for NF- } \kappa \mathrm{B}-5^{\prime} / 3^{\prime}- \\
\text { DTS donor plasmid }\end{array}$ & $\begin{array}{l}\text { ACACCGACUCCTGGAAAGTCCC } \\
\text { CAGCTGGAAAGTCCCCAGCTGG } \\
\text { AAAGTCCCCAGCTGGAAAGTCC } \\
\text { CCAGGCGACACCCCATAATTAG } \\
\text { C }\end{array}$ \\
\hline
\end{tabular}




\begin{tabular}{|c|c|l|}
\hline ROSA26_5' junction_fwd & $\begin{array}{c}\text { ROSA26 amplicon for } \\
\text { 5' junction PCR }\end{array}$ & CTAGCCTCTTGTCGCCGATT \\
\hline ROSA26_5' junction_rev & $\begin{array}{c}\text { ROSA26 amplicon for } \\
\text { 5' junction PCR }\end{array}$ & $\begin{array}{l}\text { CGGGATTCTCCTCCACGTCACCG } \\
\text { CA }\end{array}$ \\
\hline ROSA26_3' junction_fwd & $\begin{array}{c}\text { ROSA26 amplicon for } \\
\text { ' junction PCR }\end{array}$ & AGAAAACACTCGGCTGGGAG \\
\hline ROSA26_3' junction_rev & $\begin{array}{c}\text { ROSA } 26 \text { amplicon for } \\
\text { ' junction PCR }\end{array}$ & $\begin{array}{l}\text { GTTGGGTCGCATTCAAAGCTGTC } \\
\text { CTG }\end{array}$ \\
\hline EF1 $\alpha \_f w d$ & EF1 $\alpha$ amplicon for qRT-PCR & CAGCTTGGCACTTGATGTAATTC \\
\hline EF1 $\alpha \_r e v$ & EF1 $\alpha$ amplicon for qRT-PCR & CACGACACCTGAAATGGAAGA \\
\hline ACTB_fwd & ACTB amplicon for qRT-PCR & CTGGAACGGTGAAGGTGACA \\
\hline ACTB_rev & ACTB amplicon for qRT-PCR & $\begin{array}{l}\text { AAGGGACTTCCTGTAACAACGC } \\
\text { A }\end{array}$ \\
\hline
\end{tabular}

fwd, forward primer; rev, reverse primer; LP, landing pad; SA, splicing acceptor; NLS, nuclear localization signal; NP, nucleoplasmin; DTS, DNA nuclear-targeting sequence; GRE, glucocorticoid responsive element 
Supporting Table S3. Sequence information.

\begin{tabular}{|c|c|}
\hline GOI & Sequence $\left(5^{\prime}-3^{\prime}\right)$ \\
\hline ZeoR & $\begin{array}{l}\text { ATGGCCAAGTTGACCAGTGCCGTTCCGGTGCTCACCGCGCGCGACGTCGCCGGAGCGG } \\
\text { TCGAGTTCTGGACCGACCGGCTCGGGTTCTCCCGGGACTTCGTGGAGGACGACTTCGC } \\
\text { CGGTGTGGTCCGGGACGACGTGACCCTGTTCATCAGCGCGGTCCAGGACCAGGTGGTG } \\
\text { CCGGACAACACCCTGGCCTGGGTGTGGGTGCGCGGCCTGGACGAGCTGTACGCCGAG } \\
\text { TGGTCGGAGGTCGTGTCCACGAACTTCCGGGACGCCTCCGGGCCGGCCATGACCGAG } \\
\text { ATCGGCGAGCAGCCGTGGGGGCGGGAGTTCGCCCTGCGCGACCCGGCCGGCAACTGC } \\
\text { GTGCACTTCGTGGCCGAGGAGCAGGACTGA }\end{array}$ \\
\hline TagBFP & $\begin{array}{l}\text { ATGAGCGAGCTGATTAAGGAGAACATGCACATGAAGCTGTACATGGAGGGCACCGTG } \\
\text { GACAACCATCACTTCAAGTGCACATCCGAGGGCGAAGGCAAGCCCTACGAGGGCACC } \\
\text { CAGACCATGAGAATCAAGGTGGTCGAGGGCGGCCCTCTCCCCTTCGCCTTCGACATCC } \\
\text { TGGCTACTAGCTTCCTCTACGGCAGCAAGACCTTCATCAACCACACCCAGGGCATCCC } \\
\text { CGACTTCTTCAAGCAGTCCTTCCCTGAGGGCTTCACATGGGAGAGAGTCACCACATAC } \\
\text { GAAGACGGGGGCGTGCTGACCGCTACCCAGGACACCAGCCTCCAGGACGGCTGCCTC } \\
\text { ATCTACAACGTCAAGATCAGAGGGGTGAACTTCACATCCAACGGCCCTGTGATGCAG } \\
\text { AAGAAAACACTCGGCTGGGAGGCCTTCACCGAGACGCTGTACCCCGCTGACGGCGGC } \\
\text { CTGGAAGGCAGAAACGACATGGCCCTGAAGCTCGTGGGCGGGAGCCATCTGATCGCA } \\
\text { AACATCAAGACCACATATAGATCCAAGAAACCCGCTAAGAACCTCAAGATGCCTGGC } \\
\text { GTCTACTATGTGGACTACAGACTGGAAAGAATCAAGGAGGCCAACAACGAGACCTAC } \\
\text { GTCGAGCAGCACGAGGTGGCAGTGGCCAGATACTGCGACCTCCCTAGCAAACTGGGG } \\
\text { CACAAGCTTAATTAA }\end{array}$ \\
\hline loxP & ATAACTTCGTATAGCATACATTATACGAAGTTAT \\
\hline $\operatorname{lox} 2272$ & ATAACTTCGTATAGGATACTTTATACGAAGTTAT \\
\hline attP & GTGGTTTGTCTGGTCAACCACCGCGGTCTCAGTGGTGTACGGTACAAACCCA \\
\hline attPmut & GTGGTTTGTCTGGTCAACCACCGCGGACTCAGTGGTGTACGGTACAAACCCA \\
\hline attB & GGCCGGCTTGTCGACGACGGCGGTCTCCGTCGTCAGGATCATCCGG \\
\hline attB $^{\text {mut }}$ & GGCCGGCTTGTCGACGACGGCGGACTCCGTCGTCAGGATCATCCGG \\
\hline ATF4 & $\begin{array}{l}\text { ATGACGGAGATGAGCTTTTTGTCTTCCGAGGTCTTGGTAGGTGATCTGATGTCACCCTT } \\
\text { TGATCAGTCTGGGCTGGGTGCGGAAGAAAGTCTGGGACTTCTGGACGATTACCTGGAA } \\
\text { GTAGCGAAGCACTTCAAGCCGCACGGGTTTTCAAGTGATAAGGCGAAAGCGGGATCT } \\
\text { AGTGAGTGGCTTGCAGTCGATGGCCTTGTTCTCCGTCAAATAATTCCAAGGAGGATG } \\
\text { CCTTTTCCGGGACCGACTGGATGCTCGAGAAAATGGATCTCAAAGAGTTTGACCTTGA } \\
\text { TGCGCTCCTTGGCATAGACGATCTTGAAACGATGCCGGACGATCTGCTTACTACTTTG } \\
\text { GATGACACATGTGATCTGTTCGCGCCACTTGTTCAGGAGACCAATAAACAACCGCCTC } \\
\text { AAACGGTCAACCCCATTGGACACCTGCCAGAGAGTTTGACGAAGCCTGACCAGGTAG } \\
\text { CCCCCTTCACATTCCTTCAGCCATTGCCACTCAGCCCCGGCGTCCTTTCATCCACGCCT } \\
\text { GATCACAGTTTCTCCCTCGAACTGGGAAGTGAAGTCGACATCACTGAGGGAGATAGG } \\
\text { AAGCCGGATTATACAGCATATGTGGCGATGATCCCACAATGCATCAAAGAAGAGGAC } \\
\text { ACGCCAAGTGACAACGATAGTGGCATTTGTATGAGCCCTGAGAGTTACTTGGGCTCTC } \\
\text { CACAGCATTCCCCCAGTACCAGAGGTAGTCCTAACCGCAGCCTTCCATCACCAGGGGT } \\
\text { TCTTTGTGGGAGTGCCCGGCCCAAACCATACGACCCACCGGGAGAAAAGATGGTTGC } \\
\text { GGCTAAGGTTAAGGGCGAGAAATTGGATAAGAAGCTCAAAAAAATGGAGCAAAATA } \\
\text { AAACGGCTGCGACTCGCTATCGACAAAAGAAGCGGGCGGAGCAGGAAGCCCTCACAG } \\
\text { GGGAGTGTAAAGAACTGGAGAAGAAAAACGAAGCTCTTAAAGAGCGGGCAGACTCTT } \\
\text { TGGCCAAGGAGATTCAGTACCTCAAAGATCTCATCGAAGAGGTGAGGAAGGCGAGGG } \\
\text { GGAAAAAGCGGGTGCCGTAG }\end{array}$ \\
\hline ATF6c & $\begin{array}{l}\text { ATGGGAGAACCGGCCGGTGTAGCCGGTACTATGGAAAGTCCCTTCTCACCCGGCCTCT } \\
\text { TCCACAGATTGGACGAAGACTGGGATAGTGCGCTGTTTGCAGAGTTGGGATACTTTAC } \\
\text { AGATACTGATGAGCTCCAGCTTGAGGCTGCCAATGAGACATACGAGAATAACTTTGAC }\end{array}$ \\
\hline
\end{tabular}




\begin{tabular}{|c|c|}
\hline & $\begin{array}{l}\text { AACCTTGACTTCGACCTTGACCTTATGCCTTGGGAATCTGACATATGGGATATCAACA } \\
\text { ACCAGATATGTACCGTTAAGGATATAAAGGCAGAACCTCAACCGTTGTCCCCTGCATC } \\
\text { ATCCAGTTACTCAGTGAGTTCCCCCGATCAGTTGACTCTTACAGTAGTACACAGCAC } \\
\text { GTTCCGAAGAATGGACCTTCCTCCTCAGTCAGATGAGCCCACTTAGCCTGACG } \\
\text { GGGAGAACTCCAATAGCTTGAGCAGTGCTGAACCGCTGAAGGAGGATAAACCCGTCA } \\
\text { CTGGACCCCGGAACAAAACGGAGAACGGACTTACACCAAAAAAGAAAATACAGGTC } \\
\text { AACTCAAAACCTAGTATACAACCTAAACCTCTTCTGCTTCCAGCGGCTCCAAAAACGC } \\
\text { AGACTAATTCAAGCGTTCCCGCCAAAACCATCATTATTCAAACAGTTCCAACGCTTAT } \\
\text { GCCACTCGCCAAGCAGCAACCCATCATTAGTTTGCAGCCGGCCCCACGAAGGGCA } \\
\text { AACTGTACTTTGTCTCAACCGACAGTTGTCCAACTCCAAGCGCCTGGCGTTTGCCGT } \\
\text { CAGCACAACCGGTCCTGGCTGTTGCTGGAGGAGTTACACAACTGCCTAACCATGTTGT } \\
\text { TAATGTGGTCCCAGCACCATCAGCCAATTCTCCGGTCAACGGGAAGCTGAGCGTAACT } \\
\text { AAACCGGTGCTCCAAAGCACGATGCGCAACGTCGGATCCGACATAGCTGTCCTCCGA } \\
\text { AGGCAACAGCGGATGATAAAGAATAGGGAAAGCGCGTGCCAGTCCAGAAAAAAGAA } \\
\text { AAAGGAGTATATGCTTGGGCTGGAGGCACGGCTCAAGGCGGCGCTGTCTGAAAACGA } \\
\text { ACAGCTCAAGAAGGAAAACGGGACTCTGAAAAGACAACTGGATGAAGTAGTCTCAGA } \\
\text { AAACCAACGCTTGAAAGTCCCGAGCTAG }\end{array}$ \\
\hline $\mathrm{XBP} 1 \mathrm{~s}$ & 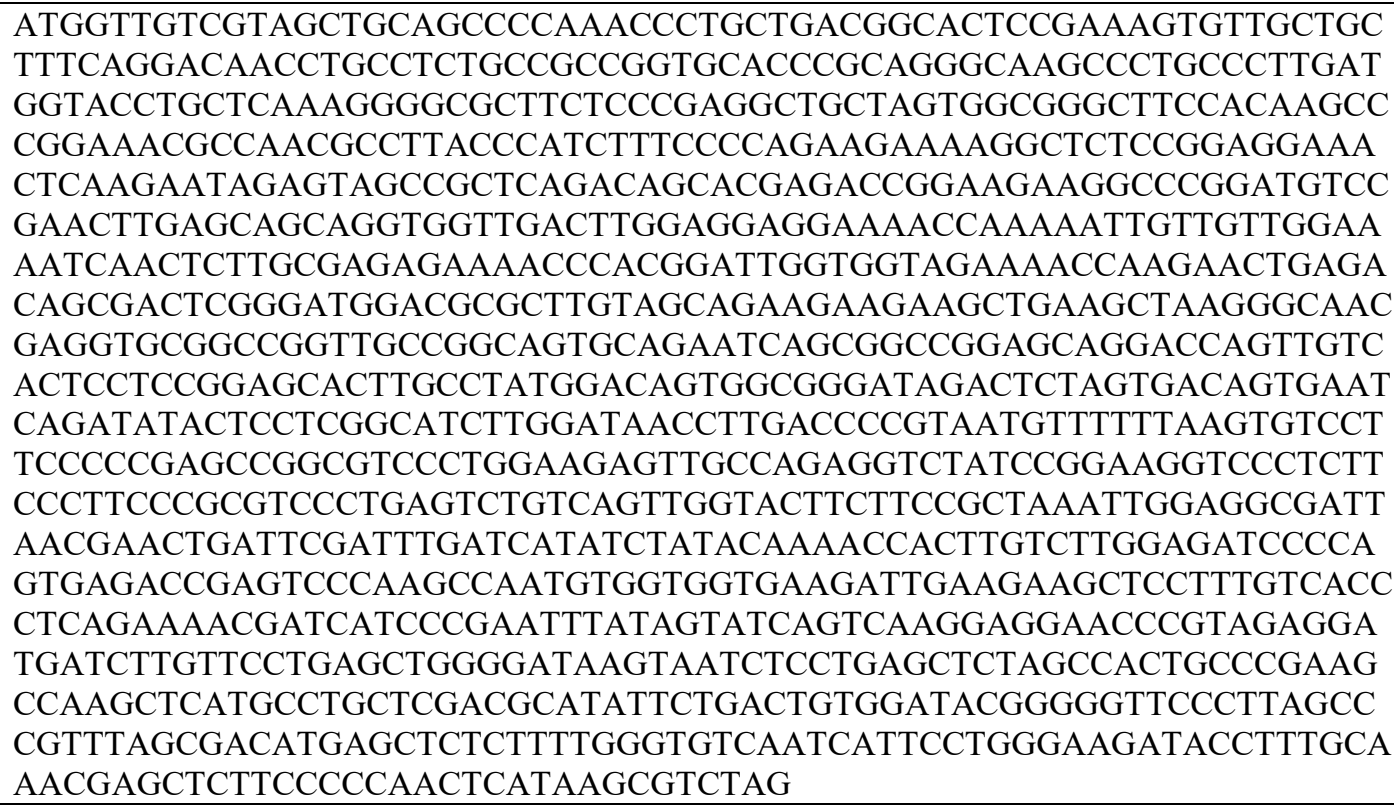 \\
\hline NLS & Sequence \\
\hline SV40 & CCCAAGAAGAAGAGGAAGGTA \\
\hline $\mathrm{cMyc}$ & CCTGCTGCCAAACGCGTTAAACTAGAC \\
\hline NP & AAAAGGCCGGCGGCCACGAAAAAGGCCGGCCAGGCAAAAAAGAAAAAG \\
\hline DTS & Sequence (linker sequences are underlined) \\
\hline SV40 & $\begin{array}{l}\text { GGTGTGGAAAGTCCCCAGGCTCCCCAGCAGGCAGAAGTATGCAAAGCATGCATCTCA } \\
\text { ATTAGTCAGCAACCA }\end{array}$ \\
\hline GRE & $\begin{array}{l}\text { ACGGGTGGTACAGAATGTTCTTTTGGCGTCGACACGGGTGGTACAGAATGTTCTTTTG } \\
\text { GC }\end{array}$ \\
\hline $\mathrm{NF}-\kappa \mathrm{B}$ & 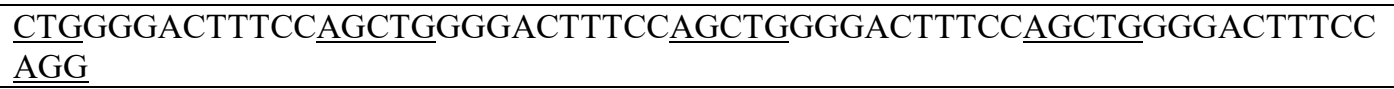 \\
\hline
\end{tabular}

GOI, gene of interest; NLS, nuclear localization signal; NP, nucleoplasmin; DTS, DNA nuclear-targeting sequence; GRE, glucocorticoid responsive element 


\section{References}

(1) Shin, S., Kim, S. H., Shin, S. W., Grav, L. M., Pedersen, L. E., Lee, J. S., and Lee, G. M. (2020) Comprehensive analysis of genomic safe harbors as target sites for stable expression of the heterologous gene in HEK293 Cells. ACS Synth. Biol. 9, 1263-1269.

(2) Gomide, M. S., Sales, T. T., Barros, L. R. C., Limia, C. G., de Oliveira, M. A., Florentino, L. H., Barros, L. M. G., Robledo, M. L., José, G. P. C., Almeida, M. S. M., Lima, R. N., Rehen, S. K., Lacorte, C., Melo, E. O., Murad, A. M., Bonamino, M. H., Coelho, C. M., and Rech, E. (2020) Genetic switches designed for eukaryotic cells and controlled by serine integrases. Commun. Biol. 3, 255.

(3) Sergeeva, D., Lee, G. M., Nielsen, L. K., and Grav, L. M. (2020) Multicopy targeted integration for accelerated development of high-producing Chinese hamster ovary cells. ACS Synth. Biol. 9, 25462561.

(4) Chu, V. T., Weber, T., Wefers, B., Wurst, W., Sander, S., Rajewsky, K., and Kühn, R. (2015) Increasing the efficiency of homology-directed repair for CRISPR-Cas9-induced precise gene editing in mammalian cells. Nat. Biotechnol. 33, 543-548.

(5) Pristovšek, N., Nallapareddy, S., Grav, L. M., Hefzi, H., Lewis, N. E., Rugbjerg, P., Hansen, H. G., Lee, G. M., Andersen, M. R., and Kildegaard, H. F. (2019) Systematic evaluation of site-specific recombinant gene expression for programmable mammalian cell engineering. ACS Synth. Biol. 8, 758774. 